\title{
Media Richness or Media Naturalness? The Evolution of Our Biological Communication Apparatus and Its Influence on Our Behavior Toward E-Communication Tools
}

\author{
-NED KOCK
}

\begin{abstract}
E-communication in businesses has been the target of intense research. The media richness hypothesis has been influential in some e-communication research circles and has also been strongly attacked by social theorists. It is argued in this paper that this theoretical polarization involving advocates of the media richness hypothesis and social theorists is due to two problems. The first is that there is a wealth of empirical evidence that provides direct support for the notion that human beings prefer the face-to-face medium for a variety of business tasks that involve communication, which seems to provide support for the media richness hypothesis. The second problem is that the media richness hypothesis is built on a vacuum, as no underlying explanation was ever presented by media richness theorists for our predisposition toward rich (or face-to-face) media. The main goal of this paper is to offer a solution to these problems by providing an alternative to the media richness hypothesis, referred to here as media naturalness hypothesis, developed based on Darwin's theory of evolution. The media naturalness hypothesis argues that, other things being equal, a decrease in the degree of naturalness of a communication medium (or its degree of similarity to the face-to-face medium) leads to the following effects in connection with a communication interaction: (1) increased cognitive effort, (2) increased communication ambiguity, and (3) decreased physiological arousal. Like the media richness hypothesis, the media naturalness hypothesis has important implications for the selection, use, and deployment of e-communication tools in organizations. However, unlike the media richness hypothesis, the media naturalness hypothesis is compatible with social theories of behavior toward e-communication tools. Among other things, this paper shows that the media naturalness hypothesis (unlike its media richness counterpart) is compatible with the notion that, regardless of the obstacles posed by low naturalness media, individuals using those media to perform collaborative tasks may achieve the same or better task-related outcomes than individuals using media with higher degrees of naturalness.
\end{abstract}

Index Terms-Computer mediated communication, electronic communication, evolution theory, media, media richness theory, social influence model.

$\mathbf{T}_{\mathrm{t}}$ he advent of the internet in the early 1990s and of the world wide web in the mid 1990s led to an explosion in the number of electronic business-to-consumer interactions. Empirical research on electronic communication (e-communication) behavior also increased considerably and experienced a significant shift in focus from laboratory experiments to field studies [1]. Several theories informed this research, including media richness theory [2], which has attracted the interest of researchers even though the theory was first proposed in the mid 1980s, well before the emergence of the internet as we know it today [3]-[10].

Manuscript received July 8, 2003; revised April 20, 2004. The author is with the Department of MIS and Decision Science, Texas A\&M International University, Laredo, TX 78041 USA (email: nedkock@tamiu.edu).

IEEE DOI 10.1109/TPC.2005.849649
The media richness theory was built around a central hypothesis, the media richness hypothesis, which states that different communication media possess different degrees of a trait called richness [2], [11], [12], that make them more or less effective conduits of information and knowledge. Several studies found general support for the media richness hypothesis [4], [13]-[15], other studies found weak support [5], [13], and yet other studies found little or no support at all for the media richness hypothesis [6], [14], [15].

The main goal of this paper is to extend prior research on human evolution and behavior toward technology [16], [17] and offer a solid theoretical basis on which the mixed findings above can be understood. The paper provides an alternative to the media richness hypothesis, referred to here as the media naturalness hypothesis, developed based on Darwin's theory of evolution by natural selection. Like the media richness hypothesis, the media naturalness hypothesis has important implications for the selection, use, and deployment of e-communication tools in organizations. However, unlike the media richness hypothesis, it is argued 
here that the media naturalness hypothesis is compatible with social theories of behavior toward e-communication tools. The "e" in e-communication stands for electronic, so the term e-communication as used here essentially refers to any form of computer mediated communication plus more traditional forms of electronic communication, such as telephone communication (since the telephone is also an electronic device).

\section{MEdia Richness Hypothesis}

The media richness hypothesis is used in this paper to summarize the main idea proposed by media richness theory, originally proposed by Daft and Lengel [2]. According to that idea, communication media can be classified along a continuum of richness, where richness is based on the ability of media to carry nonverbal cues, provide rapid feedback, convey personality traits, and support the use of natural language [2]. Matching media to collaborative tasks is based on the need to reduce uncertainty, or the absence of information to perform a task, and equivocality, or the absence of a shared understanding of what information means in connection with the task being carried out.

The media richness hypothesis argues that the face-to-face medium is the richest and most effective medium for reducing equivocality, which is assumed to be high in knowledge-intensive tasks that involve different departments or areas of an organization [7], [18], [19]. Communication media created by e-communication tools are placed somewhere in between the face-to-face medium and paper-based written media, depending on their ability to carry nonverbal cues, provide rapid feedback, convey personality traits, and support the use of natural language [4], [11], [18]. According to the media richness hypothesis, rational and effective users choose media of appropriate richness for tasks that involve communication, and, if due to accessibility constraints their choice of communication media is restricted to media of lower than appropriate richness, a decrease in task outcome quality will occur.

\section{Evidence in SuPport of the Media RICHNESS HYPOTHESIS}

Daft et al. found support for the media richness hypothesis in their investigations [4]. They found that managers who were media sensitive, (i.e., who selected appropriately rich media for collaborative tasks), in general performed better than managers who were not media sensitive. Later empirical studies lent further support to the media richness hypothesis, by providing evidence that e-communication media are more task-oriented than the face-to-face medium, and that users perceived those e-communication media to be less suitable for personal interactions necessary in business communication as compared to richer media [19], [20]. Other studies suggested that use of email and computer conferencing negatively affected group cohesiveness [21], [22] and argued that e-communication media reduced "social context cues," making them impersonal and likely to be avoided for business tasks or, if adopted, likely to lead to lower quality task outcomes than the face-to-face medium. For reviews of those studies, see [8] and [11].

More recent studies continue to provide empirical support for the media richness hypothesis. Walther et al's study, for example, suggests that even the sharing of images of group members' faces may have a positive effect on group performance in zero-history groups (i.e., groups whose members have no prior history of collaboration) [23]. A quote from another study, conducted by Graetz et al comparing face-to-face, teleconferencing, and electronic chat groups, is representative of the findings from the recent literature in connection with the media richness hypothesis:

An analysis of the recorded group discussions revealed that, although most of the groups in the electronic chat condition selected an integrative tallying procedure, an effective strategy that would likely have resulted in the successful solution of the problem, they experienced difficulties coordinating member inputs and verifying information. This slowed their progress and heightened their level of frustration and mental effort. This supports the notion that electronic chat lacks certain characteristics, present in verbal communication, that are necessary for exchanging and structuring information in synchronous groups. [24, p. 741]

\section{Evidence Against the Media RICHNESS HYPOTHESIS}

In spite of the existence of supporting empirical evidence to the media richness hypothesis, research on communication media choice and use behavior also led to results that contradicted the hypothesis. Fulk et al. [5] and Markus [13] discuss studies that found weak support for the media richness hypothesis as well as evidence contradicting the hypothesis. Other studies attempting to test, replicate, or extend the media richness hypothesis found little or no support for it [6], [14], [15]. Some found effects contrary to the notion that a lack of social presence and social context cues is necessarily bad for collaborative tasks, as communication media users can compensate for the lack of richness of the media by adapting their communication behavior (e.g., [3], [18], [25], [26]). Similarly, Markus found that managers often use email, a lean medium according to the media richness hypothesis, for complex communication in connection with managerial tasks [8]. Others found evidence that users could have rewarding and perceptually rich interaction in computer-based and 
asynchronous newsgroups, or other online social communities, whose underlying communication media were relatively low in richness according to the media richness hypothesis [22], [27].

In addition to the empirical evidence contradicting the media richness hypothesis, one main theoretical refutation has been proposed in 1994, the social influence refutation [8]. The social influence refutation of the media richness hypothesis is based on Fulk et al's social influence model, which argues that social influences can strongly shape individual behavior toward technology in ways that may be independent of technology features [5]. Examples of social influences are patterns of technology use observed in individuals that are consistent with formal and informal social norms of accepted behavior followed by a group to which the individual belongs [28]. Social influences on technology-related individual behavior have been shown to be moderated by a number of factors, particularly an individual's personal attraction to a group [29]. Markus showed that social influences might shape individual behavior toward communication media in ways that are inconsistent with the media richness hypothesis by focusing on media choices made by managers at a large risk management services provider [8]. Specifically, Markus questioned the accuracy of the media richness scale, which places email behind face-to-face interaction, suggesting that social influences can change some of email's attributes that are assumed to be static and dependent on media attributes by the media richness hypothesis. The key piece of evidence presented by Markus was that senior managers' pressure on other employees to reply quickly to email increased the medium's feedback immediacy, and therefore shifted email up from its relative position on the media richness scale. A plausible conclusion that follows from Markus' argument is that social influences, such as pressure from managers on their subordinates, can make a medium that is seen as lean based on the media richness hypothesis to become richer than face-to-face (e.g., if managers require their subordinates to use only email for communication and to avoid face-to-face communication as much as possible).

However, the social influence refutation focused on showing a fatal flaw in the media richness hypothesis, and did not aim to address one striking fact about many of the empirical studies that contradicted the media richness hypothesis. Even though those studies found evidence against the hypothesized positive link between media richness and media choice or quality of task outcomes, they also often found evidence that pointed at the perceived inadequacy of media of low richness by their users, a perception that was aligned with the media richness hypothesis [3], [8], [18], [22], [27]. This is true in Markus's study as well, where managers and employees also perceived email as a poor medium for communication, in spite of the managers' decision to promote the use of email because of some of its advantageous features such as the ability to enable distributed and asynchronous interaction [8]. That is, those studies successfully questioned the existence of a link between low media richness and two patterns, namely media avoidance and lower quality of task outcomes than in richer media, but not the perception by users that media that veered too far away from the face-to-face medium were somehow less appropriate than the face-to-face medium to support communication interactions in connection with business tasks. This paper tries to explain this phenomenon by introducing the concept of media naturalness and proposing a new hypothesis called MEDIA NATURALNESS HYPOTHESIS. In addition to explaining the phenomenon, as well as explaining evidence in support of the media richness hypothesis, the media naturalness hypothesis is shown to be compatible with Fulk et al's [5] social influence model [5]. The new hypothesis builds on the modern version of Darwin's theory of evolution by natural selection, which allows us to understand how we developed our current biological communication apparatus [30].

\section{Human Evolution and Media Naturalness}

The relevance of understanding the process that led to the evolution of our biological communication apparatus and the effect that this has on e-communication behavior comes from one important conclusion, developed in more detail below, which is that human beings have been engineered by evolutionary forces to communicate primarily in a co-located and synchronous manner, as well as through facial expressions, body language, and speech.

According to the modern version of Darwin's theory of evolution, the human species evolved through natural selection, a process in which random mutations are introduced in the genetic makeup of offspring, leading to traits that are selected based on their usefulness for survival and mating [30]-[32]. The evolutionary pace set by natural selection is usually very slow [33]-[35]. Genetic mutations that enhance an individual's chances of survival and mating, in many cases only slightly, slowly accumulate and spread through the members of a species, leading to the development of species-wide physical, behavioral, and cognitive traits over long periods of time [34]. These may span thousands or millions of years, and are contingent on breeding speed and mortality rates.

Evidence in connection with the evolution of the human species suggests that during more than 99\% of our evolutionary cycle we relied on co-located and synchronous forms of communication through facial expressions, body language, and sounds (including speech, which uses a variety of sound combinations) 
to exchange information and knowledge among ourselves [33], [36]. The human species developed a complex web of facial muscles (22 on each side of the face, more than any other animal) that allow human beings to generate over 6,000 communicative expressions; very few of these muscles are used for other purposes, such as chewing [37], [38]. There is a noticeable evolutionary direction toward the development of a biological communication apparatus that supported ever more sophisticated forms of speech, or increased communication complexity, culminating in the development of complex speech by Homo sapiens. The advent of complex speech was enabled by the development of a larynx located relatively low in the neck and an enlarged vocal tract-key morphological traits that differentiate modern humans from their early ancestors and that allow modern humans to generate the variety of sounds required to speak most modern languages [39]-[41]. The morphology of the human ear also suggests a specialized design to decode speech [41], [42].

The current evidence in connection with the evolution of the human species supports the conclusion that, since our biological communication apparatus has been used for co-located and synchronous communication using facial expressions, body language, and sounds over such a long period of time, then it should have been designed for communication interaction modes that present those characteristics. A plausible corollary would be that other communication interaction modes, including e-communication in general, would be matched to different degrees to our biological communication apparatus, some poorly, some not so poorly, depending on the degree to which they approximate face-to-face communication.

It is important to note here that optimal biological design rarely occurs in nature because evolution is a very slow process that takes time to catch up with environmental change. As a result, changes in the environment often make previous biological designs suboptimal. A leading evolutionary psychologist has made this point rather eloquently in the past:

One constraint on optimal design are evolutionary time lags ... evolution refers to change over time ... Because evolutionary changes occur slowly, requiring thousands of generations of recurrent selection pressure, existing humans are necessarily designed for the previous environments of which they are a product. Stated differently, we carry around a stone-aged brain in a modern environment. A strong desire for fat, adaptive in a past environment of scarce food resources, now leads to clogged arteries and heart attacks. [43, p. 20]
Buss's conclusion above is a general one, of which the main hypothesis proposed in this paper (i.e., the media naturalness hypothesis) can be seen as a corollary [43]. Essentially, what is argued here is that modern humans' brains are not optimally adapted for current e-communication technologies because these technologies often suppress too many of the elements found in face-to-face communication. That is, our brain has likely been to a large extent hardwired for co-located and synchronous communication employing facial expressions, body language, and speech; or, in other words, our brain is genetically programmed to excel in communication interactions that incorporate those elements. This provides the basis on which the concept of MEDIA NATURALNESS can be defined-the ability of communication media to support co-located and synchronous communication employing facial expressions, body language, and speech. It follows from the analysis of evidence in connection with our evolutionary past, that using modes of communication that veer away from natural communication is likely to put an extra burden on the brain, as our brain has been designed for that type of communication. Essentially, natural communication is equated with face-to-face communication.

A simple analogy can help highlight the importance of the above conclusion. Since we evolved two hands, not one or three hands, we also evolved to have brain functions designed for the use of two hands (as well as other connected elements, such as arms) to accomplish a number of basic tasks, such as climbing a tree by holding onto its branches. Therefore, trying to climb a tree using only one hand is likely to be more difficult and frustrating for a human being than if both hands were used. That is, the lack of naturalness of the act causes a mismatch between the biological makeup of the individual and the task being accomplished. It is argued here that communicating in ways that are not natural is analogous to this, in that it also leads to a mismatch and related consequences. This mismatch refers to our biological communication apparatus, which comprises the brain functions associated with communication, and the various communication instincts [42], [44] that have been programmed into our brain by evolutionary forces. This conclusion provides the basis for the development of the media naturalness hypothesis.

However, before we go any further, it is important to stress that e-communication tools exist for a reason, which is that they solve key communication problems that exist today (and that did not exist in our prehistoric past). For example, communication through email, with all its limitations, can take place regardless of time and physical location-that is, it can take place in an asynchronous and distributed manner-making it a convenient alternative to 
face-to-face communication in a variety of business situations. Moreover, email, with all its limitations, generates a record, and thus can be reprocessed by its recipient as many times as needed (as long as proper filing takes place), something that is not possible with face-to-face communication. Therefore, the argument put forth in this paper should not be interpreted as a call for the use of face-to-face communication only in business but an alternative explanation as to why we often should make e-communication media resemble face-to-face communication as much as possible, while at the same time preserving the advantages that led to the widespread use of communication systems such as email.

\section{EfFects of Media Naturalness on COMMUNICATION ATTRIBUTES}

The media naturalness hypothesis is an attempt to derive a general predictive statement linking a few dependent communication constructs with one main independent construct, namely the mismatch between our biological communication apparatus and communication media characteristics. The inverse of this mismatch is defined as the naturalness of a communication medium-that is, the higher the mismatch, the lower the naturalness of a communication medium. In this section, we define media naturalness and key constructs affected by it, following that with the formal enunciation of the media naturalness hypothesis.

Media Naturalness As discussed in the previous section, there is strong evidence that human beings have been engineered by evolutionary forces to communicate primarily in a co-located and synchronous manner, as well as through facial expressions, body language, and speech. Thus, it is reasonable to assume that natural communication involves at least five key elements: (1) a high degree of co-location, which would allow the individuals engaged in a communication interaction to see and hear each other, as well as share the same environment while engaging in communication, (2) a high degree of synchronicity, which would allow the individuals engaged in a communication interaction to quickly exchange communicative stimuli, (3) the ability to convey and observe facial expressions, (4) the ability to convey and observe body language, and (5) the ability to convey and listen to speech. Given this, we can define the naturalness of the communication medium created by an e-communication technology based on the degree to which the technology selectively incorporates (or suppresses) those five elements. That is, it can be stated that, other things being equal, the degree of virtual incorporation of one of the media naturalness elements correlates the degree of naturalness of an e-communication medium. The term "virtual" means that none of the five media naturalness elements will be incorporated to the e-communication medium to the same extent to which it is available in actual face-to-face communication. For example, flat representations of facial expressions, such as those provided by desktop video conferencing, are a virtual approximation of the actual three-dimensional experience of seeing live facial expressions [45], [46].

With the main independent construct of the media naturalness hypothesis defined (i.e., communication media naturalness), we can now focus on the identification of key dependent constructs that are relevant from a business perspective. This is done here as a first step, since identifying a comprehensive set of dependent constructs that are directly affected by media naturalness would require extensive empirical research and is suggested here as future research. Nevertheless, the set of dependent constructs identified below can be seen as sufficient to justify the media naturalness hypothesis as a viable alternative for the media richness hypothesis. The dependent constructs discussed here are cognitive effort, communication ambiguity, and physiological arousal.

Cognitive Effort There is a large body of evidence pointing at our ability to employ the media naturalness elements rather effortlessly in communication interactions. For example, it has been shown that human beings possess specialized brain circuits that are designed for the recognition of faces and the generation and recognition of facial expressions [37], [38], [47], which artificial intelligence research suggests require complex computations that are difficult to replicate even in powerful computers [48], [49]. The same situation is found in connection with speech generation and recognition [48]-[51].

Since our brain's circuitry has been designed by evolution to excel in communication employing the five media naturalness elements discussed above, one can reasonably conclude that selectively suppressing those elements in communication media will require the development and use of specialized brain circuits to make up for the absence of those elements and enable effective communication [17]. Those brain circuits are not hardwired into our brain but learned over time, primarily through changes in the brain's neocortex, its outer layer, where most learned circuits are concentrated. Lieberman [41], [50], [51] has shown that, as far as human communication is concerned, learned circuits are unlikely to be as efficient as the hardwired circuits endowed on us by evolution, the former usually relying on more convoluted paths than the latter. As pointed out by Pinker and Bloom, the latter, genetically coded circuits are a result of the gradual evolution of "neural mechanisms [that make communication] become increasingly automatic, unconscious, and undistracted by irrelevant aspects of world knowledge" [52, p. 477]. Moreover, most 
learned brain circuits used in communication have to be "refreshed" (or partially relearned) from time to time; otherwise they are "erased" [44], [53]. Those learned circuits usually differ from individual to individual, which can lead to inefficiencies associated with differences in sender/receiver communication brain circuitry [54]. Thus, it is plausible to conclude that since the use of more convoluted paths requires increased neural activity, decreases in media naturalness will generally lead to increased mental effort, or what we refer here to as COGNITIVE EFFORT, in connection with communication interactions.

Cognitive effort is defined here as the amount of mental activity, or, from a biological perspective, the amount of brain activity involved in a communication interaction. It can be assessed directly, with the use of techniques such as magnetic resonance imaging. Cognitive effort can also be assessed indirectly, based on perceptions of levels of difficulty associated with communicative tasks [53], [55], as well as through indirect measures such as that of fluency, proposed by Kock [18]. The fluency measure builds on the assumption previously made in many empirical studies (see, [56]) that the amount of cognitive effort associated with an intellective task correlates the amount of time required to complete the task. As such, "fluency" is defined as the amount of time taken to convey a certain number of words through different communication media, which is assumed to correlate (and serve as a surrogate measure of) the amount of time taken to convey a certain number of ideas through different media [18].

Empirical studies, conducted by Kock, of process improvement groups interacting through different communication media are particularly well aligned with the notion that a decrease in media naturalness will generally lead to an increase in cognitive effort [1], [18]. Those studies showed that fluency is, on average, 18 times higher face-to-face than over email in complex group tasks. Even in the case of proficient typists, who can usually type at least half as fast as they can speak, Kock's research suggests fluency in complex collaborative tasks conducted face-to-face to be about 10 times higher than over email, regardless of other factors such as cultural background and familiarity with collaborators [57]. According to this estimate, if exchanging 600 words face-to-face required about 6 minutes, exchanging the same number of words over email would take approximately 1 hour. These figures are comparable with those found in Kock's studies [57].

Communication Ambiguity Individuals brought up in different cultural environments usually possess different information processing schemas that they have learned over their lifetimes. Different schemas make individuals interpret information in different ways, particularly when information is expected but not actually provided. Bartlett has unequivocally demonstrated this phenomenon, perhaps for the first time, in his famous experiments involving the American Indian folk tale "The War of the Ghosts" [58]. Essentially, the experiments showed that subjects who held different information processing schemas would interpret the tale, which is filled with strange gaps and bizarre causal sequences, in substantially different ways. In Bartlett's experiments, individuals were expecting certain pieces of information to be provided to them [58]. When they did not get the information that they were expecting, they filled in the gaps based on their existing information processing schemas and the information that they were given (see also [59]). This led to significant differences in the way different individuals interpreted the tale.

The human brain has a series of hardwired information processing schemas that are designed to solve problems that have occurred recurrently during the millions of years that led to the evolution of the human species [60], [61]. Several of these problems addressed by evolutionary adaptations are related to the communication process [52]. Our hardwired schemas involved in the communication process make us search for stimuli that will enable us to obtain enough information to effectively interpret the message being communicated, and several of the stimuli we automatically search for are those present in actual face-to-face communication, such as contextual cues (available in co-located communication), immediate feedback (available in synchronous communication) in the form of facial expressions and body language, and vocal intonations [51]. When several of these stimuli are not present, by being selectively suppressed by e-communication technologies, individuals fill in the gaps much like the subjects in Bartlett's experiments [58].

The problem is that in the absence of information-giving stimuli, filling in the gaps is likely to lead to a higher proportion of misinterpretations, and thus ambiguity, than if the stimuli were not suppressed-as Bartlett's [58] and other studies (see [44] and [59]) show. While different individuals are likely to look for the same types of communicative stimuli, their interpretation of the message being communicated in the absence of those stimuli will be largely based on their learned schemas, which are likely to differ from those held by other individuals (no two individuals, not even identical twins raised together, go through the exact same experiences during their lives). That is, a decrease in medium naturalness, caused by the selective suppression of media naturalness elements in a communication medium, is likely to lead to an increase in the probability of misinterpretations of communicative cues, and thus an increase in COMMUNICATION AMBIGUITY. 
The above conclusion is consistent with the empirical observation that certain feedback comments, especially those involving constructive criticism, which are often used effectively in face-to-face interaction together with other nonverbal cues that soften their tone, are interpreted in different (and often negative) ways when provided via email in business-related discussions-sometimes as very critical and blunt, sometimes as implying indifference [1]. The conclusion above is also well aligned with the consistent empirical finding that e-communication in general is perceived as more ambiguous than face-to-face communication [3], [18], [22], [24], [27], [57]. While there are studies that show that individuals can voluntarily or involuntarily compensate for this increase in communication ambiguity by means of constructing better thought out messages [18], [62], and by becoming familiar with the medium and their partners [3], [22], to the best of our knowledge there have been no studies suggesting that the suppression of media naturalness elements causes a reduction in communication ambiguity (i.e., the opposite effect to what we hypothesize here). That is, even though there is evidence suggesting that the effects of greater communication ambiguity can be moderated by compensatory adaptation behavior, the evidence suggesting that lower communication media naturalness leads to greater communication ambiguity is beyond much doubt.

\section{Physiological Arousal To say that our genes} influence the formation of a phenotypic trait (i.e., a biological trait that defines a morphological, behavioral, physiological, etc. characteristic) does not mean the same as saying that the trait in question is "innate." In fact, very few phenotypic traits are innate (e.g., blood type); the vast majority, including most of those in connection with our biological communication apparatus, need interaction with the environment to be fully and properly developed. For example, the human eye is a complex organ that was designed by evolutionary forces over millions of years [32], [63]. Like many other organs, the complex set of genes that guides the development of the human eye assumes the presence of certain environmental stimuli and circumstances, which were likely present in our prehistoric past during most of our evolutionary history. For example, it has been shown that if the eye is not properly stimulated with light in the first years of life, it will not develop properly, in some cases leading to severe eyesight problems and even blindness [32].

The above is also true for the human biological communication apparatus. While there is substantial evidence suggesting that our biological communication apparatus is designed for face-to-face communication, there is also ample evidence that such an apparatus (including the neural functional language system) cannot be fully developed without a significant amount of practice [42]. There is little doubt that a fully developed biological communication apparatus has been particularly important in terms of survival and mating for our prehistoric ancestors, as it is for us today [33], [64], [65]. Thus, evolution must have developed mechanisms to compel human beings to practice the use of their biological communication apparatus, mechanisms that are similar to those compelling animals to practice those skills that play a key role in connection with survival and mating [66], [67]. Among these mechanisms, one of the most important is that of physiological arousal, which is often associated with excitement and pleasure [33], [65].

It is a plausible conclusion from the above discussion that engaging in communication interactions, particularly in face-to-face situations, is likely to trigger physiological arousal in human beings. This conclusion underlies the theoretical hypothesis that modern humans possess what Pinker refers to as a "language instinct," and can be taken further through the associated conclusion that each face-to-face communication element (e.g., the use of facial expressions to convey thoughts and feelings) contributes to physiological arousal [42]. Indeed, there is evidence that face-to-face communication elements such as certain types of facial expressions, oral utterances, and body language expressions, even when used in isolation, evoke physiological arousal in human beings [37], [38], [68]. Thus, it would be reasonable to also conclude that communication interactions in which certain elements of natural face-to-face communication are suppressed (e.g., the ability to employ/see facial expressions) involve a corresponding suppression of physiological arousal, and, in turn, a consequent decrease in the perceived excitement in connection with the communication interaction. In other words, suppression of media naturalness elements is likely to make communication interactions duller than if those elements were present.

Obviously, as with other conclusions put forth in this paper, the above conclusion assumes that other things are equal. For instance, the topic of a communication interaction and the identity of the other person are factors that may influence physiological arousal more strongly than the communication medium itself, which is a point that is not disputed here and is perfectly compatible with the hypothesis put forth in this paper. Having said that, it is interesting to point out that the above conclusion is consistent with and provides a plausible explanation for the ample evidence suggesting that, other things being equal, e-communication systems users consistently perceive computer mediated communication in general as less "exciting," "duller," or less "emotionally fulfilling" than face-to-face communication [1], [22], [69]-[73]. 
Decreases in physiological arousal may influence media choices toward media of high naturalness, but, when choice is limited to low naturalness media, decreases in physiological arousal may arguably influence task outcome quality positively under the appropriate circumstances. A decrease in physiological arousal may induce the members of a group to engage in more focused communication, particularly when an e-communication medium is used to support task-oriented interaction, as opposed to relationship-oriented interaction [22]. That is, the lack of excitement resulting from the use of an e-communication medium to support a particular group task may be associated with a higher degree of communication focus on the task at hand, rather than gossip or tangential topics, somehow counteracting the likely negative effects on task outcome quality associated with increase cognitive effort and communication ambiguity. Kock's study of process improvement groups provides evidence that supports in part this conjecture [1].

\section{Media Naturalness Hypothesis}

Now that the three main dependent constructs of cognitive effort, communication ambiguity, and physiological arousal have been identified and defined, we can formally enunciate the media naturalness hypothesis as follows. The hypothesis assumes that the face-to-face medium is the most natural medium of all.

Other things being equal, a decrease in the degree of naturalness of a communication medium leads to the following effects in connection with a communication interaction: (1) an increase in cognitive effort, (2) an increase in communication ambiguity, and (3) a decrease in physiological arousal.

As discussed before, the media naturalness construct is made up of five main elements: co-location, synchronicity, and the ability to convey facial expressions, body language, and speech. Thus, two assumptions can be made which are useful for managers who need to decide which features to have on their e-communication systems in the face of limited resources. The first assumption is that, other things being equal, an e-communication medium that incorporates one of the media naturalness elements - that is, co-location, synchronicity, and the ability to convey facial expressions, body language, and speech-will have a higher degree of naturalness than another e-communication medium that does not incorporate that element. The second assumption is that, other things being equal, an e-communication medium that incorporates one of the five media naturalness elements to a larger degree than another e-communication medium will have the highest degree of naturalness of the two e-communication media, being full incorporation one in which the element is identical to what would be available in the face-to-face medium.

The media naturalness hypothesis can be used as a basis for management decisions regarding which new features to add to an e-communication tool depending on resource constraints. For example, let us assume a web-based application that allows two individuals to communicate through text-based chat in a business-to-consumer type of interaction, such as that involving a customer service representative of an online broker and one of its customers who needs to learn how to purchase a particular investment instrument. According to the media naturalness hypothesis, if a nearly identical application is developed, where the only difference is the ability to convey facial expressions though streamed video (in addition to the text-based chat-feature), this latter application will create a communication medium with a higher degree of naturalness than that of the former, text-based chat only, application. A likely consequence will be higher perceived quality by customers in connection with the online interaction, for example, due to the lower cognitive effort required from them in the interaction.

The media naturalness hypothesis also provides the basis for management decisions regarding partial incorporation of a naturalness element to an e-communication medium depending on resource constraints. Each of the five naturalness elements (i.e., co-location, synchronicity, and the ability to convey facial expressions, body language, and speech) can be incorporated into an e-communication medium to varying degrees, or partially; full incorporation means that the element is identical to what would be available in the face-to-face medium. For example, between two video conferencing applications, the one whose video and sound quality approach most closely what is seen and heard in actual face-to-face communication is the one with the highest degree of naturalness of the two.

\section{Discussion}

If the media naturalness hypothesis is to be considered a viable and useful alternative to the media richness hypothesis, key differences between the hypotheses must be explicitly identified. While the media naturalness hypothesis may seem similar to the media richness hypothesis, at least two key differences exist between the two regarding main dependent constructs, and classification of different media according to a given scale of either richness or naturalness. These differences are discussed individually below.

The first key difference refers to the main dependent constructs of the hypotheses. The media richness hypothesis has two main dependent constructs, which are hypothesized to vary depending on the degree of 
richness of the communication medium being used. These constructs are: (1) media choice, which is hypothesized to match the richness requirements of a task in the case of effective workers and (2) task outcome quality, which is hypothesized to be negatively affected if choice is limited to media that possess a level of richness that is lower than optimal for the task [4], [7], [8], [11].

The media naturalness hypothesis, on the other hand, does not relate low media naturalness with certain types of behavior or task outcomes, like the media richness hypothesis does, but with high cognitive effort and communication ambiguity, and with low physiological arousal. This in turn may or may not lead to certain types of behavior or task outcomes. For example, as mentioned before, empirical studies conducted by Kock of process improvement groups interacting through different communication media showed that fluency (the number of words an individual can convey over a particular communication medium per unit of time) is about 10 times higher face-to-face than over email in complex group tasks, even when the effect that "typing is slower than speaking" is controlled for [1], [18]. Yet, the studies found that most groups voluntarily chose email to perform their tasks, even though interviews suggested that they consistently perceived email as an ambiguous and poor communication medium, and that the task outcome quality was slightly better for the email groups when compared with the face-to-face groups. Interviews also suggested that email was chosen primarily because of what most perceived as advantages, such as the ability to support distributed and asynchronous communication. The explanation given for these seemingly paradoxical results was that individuals compensated for the lack of naturalness of the communication medium used by preparing better thought out, more focused, and better structured contributions than in face-to-face meetings [1], [18]. The studies provide evidence that while cognitive effort was increased, which is consistent with the media naturalness hypothesis, media choice, and task outcome quality were different from predicted by the media richness hypothesis. The media naturalness hypothesis provides a basis on which media choices and task outcomes can be more deeply understood as the result of the interplay of biological, social, and environmental influences.

The other key difference between the media naturalness hypothesis and the media richness hypothesis is that the latter assumes that different communication media can be classified according to a continuum of media richness, based primarily on communication media features that make them more or less rich-particularly the information-carrying capacity of the media. This opens the door for the conclusion that communication media that incorporate more of those features that increase their richness (e.g., feedback immediacy or synchronicity) than the face-to-face medium will be even better than face-to-face interaction in some circumstances. For instance, they may allow individuals to deal with tasks of extremely high equivocality by supporting parallel communication interactions with several individuals at the same time. The media naturalness hypothesis, however, argues that the face-to-face medium is, other things being equal (including the communication topic and task), the one likely to lead to the least cognitive effort and communication ambiguity, and the most physiological arousal during communication. The reason is that the face-to-face medium is precisely the medium used for communication during the vast majority of our evolutionary history. This implies that e-communication tools with features that allow group members to synchronously generate and access substantially more information than in face-to-face interactions will also lead to problems, likely due to information overload and other negative effects. That is, the media naturalness hypothesis allows us to place the face-to-face medium at the center of a one-dimensional scale of naturalness where the distance from the center (either to the left or right) could be seen as a measure of decreased naturalness. Anything less or more, so to speak, than face-to-face communication would be likely to lead to problems in communication interactions.

This conclusion is consistent with previous studies of group decision support systems [72], [74]. Those systems are typically used to enhance face-to-face communication by allowing individuals in the same room to interact synchronously through computers without having to share airtime with each other (i.e., all individuals can contribute ideas at the same time, which a human facilitator manages for the group with the help of the system). Even if used by pairs of individuals, these systems are generally believed to allow for the exchange of significantly more information than pure face-to-face meetings [75]. Consistent with the conclusion above based on the media naturalness hypothesis (i.e., that more can be less, so to speak), a study reported by Reinig et al. found that the use of group decision support systems makes meetings less exciting for the participants [72]. Other empirical findings in connection with group decision support systems also provide support for that conclusion. A consistent finding from studies of the impact of group decision support systems on meetings has been that they increase the number of ideas generated but do not improve the quality of the outcomes produced through the meetings [74], which led Dennis to conclude that the use of the systems leads to information overload [76]. That is, on the surface, individuals seem to exchange more information, but the information is never used to achieve better task outcomes because the rate of information exchange is higher than the information processing capacity of the individuals. 


\section{IMPLICATIONS FOR RESEARCHERS}

The media naturalness hypothesis cannot fully explain e-communication behavior. Arguing otherwise would be akin to proposing a modern-day version of biological determinism. Other factors in connection with the use of e-communication media need to be considered, such as social influences [5], [8]. For example, the media naturalness hypothesis could not have been used to fully explain the behavior of the employees in Markus's study, who used email because of pressure from senior managers in spite of perceiving it as a poor communication medium [8]. That is, it was primarily a social influence that led them to behave in the way they did in connection with media choice [5]. Moreover, they used email in a relatively effective way for complex communication, in spite of their negative perceptions about the medium, which suggests another phenomenon that is not predicted by the media naturalness hypothesis, namely the phenomenon of compensatory adaptation [18], [62].

Nevertheless, a key contribution of the media naturalness hypothesis, and one of its most important implications for researchers, is that it provides a missing link that may pave the way for the integration of different e-communication theories. Previous theoretical reviews have categorized e-communication theories in similar ways. Webster and Trevino grouped them into two categories according to their emphasis on rational or social explanations: theories proposing rational explanations of media choice and theories proposing social explanations for media choice [77]. Carlson and Davis classified theories into two similar categories: trait theories and social interaction theories [12]. These categorizations suggest key differences between socially deprived theories, of which Daft and Lengel's [2] media richness theory is often seen as the paragon, and theories placing emphasis on social elements as determinants of behavior toward e-communication media. This "theoretical polarization" was later highlighted in another theoretical review, suggesting that these two main types of theories have "often been pitted against each other rather than considered as complementary in more comprehensive studies" [10, p. 163]. However, in spite of attempts to combine both types of theories [10], [77], other studies provide evidence that the media richness hypothesis cannot be effectively combined with hypotheses espoused by social theories without radical revisions [11], [78].

The development of the media naturalness hypothesis is a first step in the pursuit of a solution to this problem. Evidence of this is that the media naturalness hypothesis, as discussed earlier, is not only compatible with Fulk et al.'s social influence model, but also adds to our understanding of e-communication behavior phenomena that are not completely explained by that model [5].
The above must be followed by a caveat regarding the limitations of the theoretical perspective taken here. The argument presented in this paper focuses on a human-to-human communication perspective, which is arguably a narrow perspective of human communication and cognition. Different and possibly broader perspectives exist, such as the systemic perspective proposed by Hutchins, who deems a culturally diverse group of individuals as a key unit of cognition [79], and the "metaindexicality" perspective proposed by Henderson, who sees visual representations as cognitive artifacts that allow for rich communication at multiple cognitive levels [80]. One could also take a human-to-object perspective, by looking at interactions between humans and inanimate objects as legitimate instances of communication. The relatively narrow human-to-human communication perspective is adopted here because it is arguably the perspective adopted by the media richness hypothesis, for which this paper attempts to propose a viable alternative.

\section{IMPLICATIONS FOR MANAGERS}

The media naturalness hypothesis leads to predictions that are particularly relevant for communicative tasks brought about by the advent of e-business. The hypothesis leads to the prediction that cognitive effort and communication ambiguity should increase, and physiological arousal decrease, with decreases in e-communication media naturalness. In business-to-consumer interactions conducted online, increased cognitive effort and communication ambiguity and (possibly) decreased physiological arousal (especially in entertainment-related interactions) may lead to lower perceived quality and dissatisfaction from customers. Since the internet makes it much easier for customers to change suppliers, who are literally a few clicks away, the use of e-communication media of lower naturalness than those provided by the competition can have negative consequences for companies that rely heavily on online interaction with their customers to increase or maintain their revenues. This conclusion is aligned with, and partially explains, the constant calls in the popular business literature for the use of more natural forms of online communication between business and consumers [81]-[83]. That is, even though a decrease in communication medium naturalness may not have a negative effect on task outcome quality [18], [62], it will lead to other problems in certain situations (e.g., online business-to-consumer interactions).

The media naturalness hypothesis provides the basis on which managers with limited resources can decide how to maximize the naturalness of their companies' online communication with their customers. One area in which these decisions have to be made in many businesses, regardless of type and size, is that of online customer support, where customer support 
representatives interact with customers electronically. The widespread availability of generic video players and instant-messaging technologies allow for the selective incorporation of synchronicity and the ability to convey speech and facial expressions to these internet-based interactions, which, according to the media naturalness hypothesis, is likely to lead to a decrease in the amount of cognitive effort and communication ambiguity in connection with communication interactions where customers are seeking support. This is likely to contribute to an increase in perceived customer service quality. An expected consequence of increased perceived customer service quality is maintenance of or increase in market share. This conclusion is consistent with studies of the impact that customer service quality has on the bottom line of companies in the financial services sector [84], [85], a sector that today relies heavily on e-communication tools to provide customer support through the internet.

The media naturalness hypothesis also provides the basis on which managers, as well as venture capitalists, can predict the likely evolution (not Darwinian) of e-communication technologies and thus better target their investments in those types of technologies. It can be concluded, based on this paper, that this evolution will be toward e-communication tools that achieve the maximum naturalness at the lowest cost possible. Although this may not be obvious at first glance, email fits this prediction reasonably well because email is more natural (e.g., it provides a higher degree of synchronicity) and arguably less costly today than paper-based mail, which is what it was meant to replace [73], [86]. This conclusion also explains the relative commercial success of sophisticated text-based chat tools that add synchronicity to online business-to-consumer interactions, making it easier and more exciting for customers to obtain information about products and services [87], [88]. Finally, it explains the relative commercial success of virtual news anchors such as "Ananova," whose cost is a fraction of their human counterparts, since many internet users seem to prefer to listen to news online while looking at a virtual newscaster rather than the arguably more cognitively demanding and less exciting option of reading them on a webpage [89], [90].

\section{ACKNOWLEDGMENT}

The author is indebted to the anonymous reviewers and particularly to the Editor, K. S. Campbell, for their many valuable suggestions. He would also like to thank Amotz Zahavi, Geoffrey Miller, and Donald Hantula for comments and suggestions regarding the connection between evolutionary biology and evolutionary psychology principles and some of the ideas proposed in this article; Allen Lee for invaluable comments and suggestions on an earlier version of this article; and John Nosek for many interesting conversations and ideas in connection with e-communication and e-collaboration. A previous version of this article was presented by the author and published in the Proceedings of the 23rd International Conference on Information Systems, Barcelona, Spain, 2002. The author wishes to thank the audience in that presentation for their insightful comments and suggestions.

\section{REFERENCES}

[1] N. Kock, Process Improvement and Organizational Learning: The Role of Collaboration Technologies. Hershey, PA: Idea Group, 1999.

[2] R. L. Daft and R. H. Lengel, "Organizational information requirements, media richness and structural design," Manage. Sci., vol. 32, no. 5, pp. 554-571, 1986.

[3] J. R. Carlson and R. W. Zmud, "Channel expansion theory and the experiential nature of media richness perceptions," Acad. Manage. J., vol. 42, no. 2, pp. 153-170, 1999.

[4] R. L. Daft, R. H. Lengel, and L. K. Trevino, "Message equivocality, media selection, and manager performance: Implications for information systems,” MIS Quart., vol. 11, no. 3, pp. 355-366, 1987.

[5] J. Fulk, J. Schmitz, and C. W. Steinfield, "A social influence model of technology use," in Organizations and Communication Technology, J. Fulk and C. Steinfield, Eds. Newbury Park, CA: Sage, 1990, pp. 117-140.

[6] S. T. Kinney and A. R. Dennis, "Re-evaluating media richness: Cues, feedback, and task," in Proc. Hawaii Int. Conf. Syst. Sci., J. F. Nunamaker and R. H. Sprague, Eds., Washington, DC, 1994, pp. 21-30.

[7] R. H. Lengel and R. L. Daft, "The selection of communication media as an executive skill," Acad. Manage. Exec., vol. 2, no. 3, pp. 225-232, 1988.

[8] M. L. Markus, "Electronic mail as the medium of managerial choice," Org. Sci., vol. 5, no. 4, pp. 502-527, 1994.

[9] R. E. Rice, "Task analyzability, use of new media, and effectiveness: A multi-site exploration of media richness," Org. Sci., vol. 3, no. 4, pp. 475-500, 1992.

[10] L. K. Trevino, J. Webster, and E. W. Stein, "Making connections: Complementary influences on communication media choices, attitudes, and use," Org. Sci., vol. 11, no. 2, pp. 163-182, 2000.

[11] A. S. Lee, "Electronic mail as a medium for rich communication: An empirical investigation using hermeneutic interpretation," MIS Quart., vol. 18, no. 2, pp. 143-157, 1994.

[12] P. J. Carlson and G. B. Davis, "An investigation of media selection among directors and managers: From 'self to 'other' orientation,” MIS Quart., vol. 22, no. 3, pp. 335-362, 1998. 
[13] M. L. Markus, "Toward a critical mass theory of interactive media," in Organizations and Communication Technology, J. Fulk and C. Steinfield, Eds. Newbury Park, CA, 1990, pp. 194-218.

[14] A. R. Dennis, S. T. Kinney, and Y. C. Hung, "Gender differences and the effects of media richness," Small Group Res., vol. 30, no. 4, pp. 405-437, 1999.

[15] S. T. Kinney and R. T. Watson, "Dyadic communication: The effect of medium and task equivocality on task-related and interactional outcomes," in Proc. 13th Int. Conf. Inform. Syst., J. I. DeGross, J. D. Becker, and J. J. Elam, Eds., New York, 1992, pp. 107-117.

[16] N. Kock, "The ape that used email: Understanding e-communication behavior through evolution theory," Commun. AIS, vol. 5, no. 3, pp. 1-29, 2001.

[17] — "The psychobiological model: Toward a new theory of computer-mediated communication based on Darwinian evolution," Org. Sci., vol. 15, no. 3, pp. 327-348, 2004.

[18] — "Can communication medium limitations foster better group outcomes? An action research study," Inform. Manage., vol. 34, no. 5, pp. 295-305, 1998.

[19] R. E. Rice and D. E. Shook, "Relationship of job categories and organizational levels to use of communication channels, including electronic mail: A meta-analysis and extension," J. Manage. Studies, vol. 27, no. 2, pp. 195-230, 1990.

[20] R. E. Rice, "Media appropriateness: Using social presence theory to compare traditional and new organizational media,” Human Commun. Res., vol. 19, no. 4, pp. 451-484, 1993.

[21] L. Sproull and S. Kiesler, "Reducing social context cues: Electronic mail in organizational communication," Manage. Sci., vol. 32, no. 11, pp. 1492-1512, 1986.

[22] J. B. Walther, "Computer-mediated communication: Impersonal, interpersonal, and hyperpersonal interaction," Commun. Res., vol. 23, no. 1, pp. 3-43, 1996.

[23] J. B. Walther, C. Slovacek, and L. C. Tidwell, "Is a picture worth a thousand words? Photographic images in long term and short term virtual teams," Commun. Res., vol. 28, no. 1, pp. 105-134, 2001.

[24] K. A. Graetz, E. S. Boyle, C. E. Kimble, P. Thompson, and J. L. Garloch, "Information sharing in face-to-face, teleconferencing, and electronic chat groups," Small Group Res., vol. 29, no. 6, pp. 714-743, 1998.

[25] S. Weisband, "Overcoming social awareness in computer-supported groups: Does anonymity really help?," Comput. Supported Coop. Work, vol. 2, no. 2, pp. 285-297, 1994.

[26] S. P. Weisband, S. K. Schneider, and T. Connolly, "Computer-mediated communication and social information: Status salience and status differences,” Acad. Manage. J., vol. 38, no. 4, pp. 1124-1151, 1995.

[27] H. Rheingold, The Virtual Community: Homesteading on the Electronic Frontier. Reading, MA: Addison-Wesley, 1993.

[28] A. Bandura, Social Foundations of Thought and Action. Englewood Cliffs, NJ: Prentice-Hall, 1986.

[29] J. Fulk, "Social construction of communication technology," Acad. Manage. J., vol. 36, no. 5, pp. 921-938, 1993.

[30] E. Mayr and W. B. Provine, The Evolutionary Synthesis: Perspectives on the Unification of Biology. Cambridge, MA: Harvard Univ. Press, 1998.

[31] C. Darwin, On the Origin of Species by Means of Natural Selection. Cambridge, MA: Harvard Univ. Press, 1859.

[32] R. Dawkins, The Selfish Gene. New York: Oxford Univ. Press, 1989.

[33] N. T. Boaz and A. J. Almquist, Biological Anthropology: A Synthetic Approach to Human Evolution. Englewood Cliffs, NJ: Prentice-Hall, 1997.

[34] T. Dobzhansky, Mankind Evolving: The Evolution of the Human Species. New Haven, CT: Yale Univ. Press, 1971.

[35] K. Lorenz, The Waning of Humaneness. Boston, MA: Little, Brown, 1983.

[36] J. Cartwright, Evolution and Human Behavior: Darwinian Perspectives on Human Nature. Cambridge, MA: MIT Press, 2000.

[37] B. Bates and J. Cleese, The Human Face. New York, NY: DK Publishing, 2001.

[38] D. McNeill, The Face: A Natural History. Boston, MA: Little, Brown and Company, 1998.

[39] J. T. Laitman, "The anatomy of human speech,” Natural History, vol. 20, no. 7, pp. 20-27, 1984.

[40] J. Laitman, "The anatomy of human speech," in The Human Evolution Source Book, R. L. Ciochon and J. G. Fleagle, Eds. Englewood Cliffs, NJ: Prentice-Hall, 1993, pp. 56-60.

[41] P. Lieberman, Eve Spoke: Human Language and Human Evolution. New York: Norton, 1998.

[42] S. Pinker, The Language Instinct. New York: William Morrow, 1994.

[43] D. M. Buss, Evolutionary Psychology: The New Science of the Mind. Needham Heights, MA: Allyn \& Bacon, 1999.

[44] S. Pinker, How the Mind Works. New York: Norton, 1997.

[45] S. Bryson, "Virtual reality in scientific visualization," Communications of the ACM, vol. 39, no. 5, pp. 62-71, 1996.

[46] Y. Mass and A. Herzberg, "VRCommerce: Electronic commerce in virtual reality," in Proc. 1st ACM Conf. Electron. Commerce, New York, 1999, pp. 103-109.

[47] R. Le Grand, C. J. Mondloch, D. Maurer, and H. P. Brent, "Early visual experience and face processing," Nature, vol. 410, no. 19, p. 890, 2001.

[48] R. Kurzweil, The Age of Spiritual Machines. New York: Viking, 1999.

[49] S. Russel and P. Norvig, Artificial Intelligence: A Modern Approach. Englewood Cliffs, NJ: Prentice-Hall, 1995.

[50] P. Lieberman, Uniquely Human: The Evolution of Speech, Thought, and Selfless Behavior. Cambridge, MA: Harvard Univ. Press, 1991.

[51] — Human Language and Our Reptilian Brain: The Subcortical Bases of Speech, Syntax, and Thought. Cambridge, MA: Harvard Univ. Press, 2000. 
[52] S. Pinker and P. Bloom, "Natural language and natural selection," in The Adapted Mind: Evolutionary Psychology and the Generation of Culture, J. H. Barkow, L. Cosmides, and J. Tooby, Eds. New York: Oxford Univ. Press, 1992, pp. 451-493.

[53] D. L. Schacter, The Seven Sins of Memory: How the Mind Forgets and Remembers. New York: Houghton Mifflin, 2001.

[54] R. Kotulak, Inside the Brain: Revolutionary Discoveries of How the Mind Works. Kansas City, KS: Andrews McMeel, 1997.

[55] P. Todd and I. Benbasat, "Evaluating the impact of DSS, cognitive effort, and incentives on strategy selection," Inform. Syst. Res., vol. 10, no. 4, pp. 356-374, 1999.

[56] A. Leganchuk, S. Zhai, and W. Buxton, "Manual and cognitive benefits of two-handed input: An experimental study," ACM Trans. Comput.-Human Interaction, vol. 5, no. 4, pp. 326-359, 1998.

[57] N. Kock, "Asynchronous and distributed process improvement: The role of collaborative technologies," Inform. Syst. J., vol. 11, no. 2, pp. 87-110, 2001.

[58] F. Bartlett, Remembering: A Study in Experimental and Social Psychology. Cambridge, MA: Cambridge Univ. Press, 1932.

[59] H. Gardner, The Mind's New Science. New York: Basic Books, 1985.

[60] L. Cosmides and J. Tooby, "Cognitive adaptations for social exchange," in The Adapted Mind: Evolutionary Psychology and the Generation of Culture, J. H. Barkow, L. Cosmides, and J. Tooby, Eds. New York: Oxford Univ. Press, 1992, pp. 163-228.

[61] J. Tooby and L. Cosmides, "The psychological foundation of culture," The Adapted Mind: Evolutionary Psychology and the Generation of Culture, pp. 19-136, 1992.

[62] N. Kock, "Compensatory adaptation to a lean medium: An action research investigation of electronic communication in process improvement groups," IEEE Trans. Profess. Commun., vol. 44, no. 4, pp. 267-285, 2001.

[63] R. Dawkins, The Blind Watchmaker. New York: Norton, 1986.

[64] R. I. M. Dunbar, "Coevolution of neocortical size, group size and language in humans," Behav. Brain Sci., vol. 16, no. 4, pp. 681-735, 1993.

[65] G. F. Miller, The Mating Mind: How Sexual Choice Shaped the Evolution of Human Nature. New York: Doubleday, 2000.

[66] K. Lorenz, Studies in Animal and Human Behavior. Cambridge, MA: Harvard Univ. Press, 1970.

[67] E. O. Wilson, Sociobiology: The New Synthesis. Cambridge, MA: Harvard Univ. Press, 2000.

[68] C. Zimmer, Evolution: The Triumph of an Idea. New York: HarperCollins Publishers, 2001.

[69] C. A. Ellis, S. J. Gibbs, and G. L. Rein, "Groupware: Some issues and experiences," Commun. ACM, vol. 34, no. 1, pp. 38-58, 1991.

[70] S. Kiesler, J. Siegel, and T. W. McGuire, "Social psychological aspects of computer-mediated communication," in Computer-Supported Cooperative Work: A Book of Readings, I. Greif, Ed. San Francisco, CA: Morgan Kaufmann, 1988, pp. 657-682.

[71] M. L. Markus, "Finding a happy medium: Explaining the negative effects of electronic communication on social life at work," ACM Trans. Inform. Syst., vol. 12, no. 2, pp. 119-149, 1994.

[72] B. A. Reinig, R. O. Briggs, M. M. Shepherd, J. Yen, and J. F. Nunamaker Jr., "Affective reward and the adoption of group support systems: Productivity is not always enough," J. Manage. Inform. Syst., vol. 12, no. 3, pp. 171-185, 1995.

[73] L. Sproull and S. Kiesler, "Computers, networks and work," Sci. Amer., vol. 265, no. 3, pp. 84-91, 1991.

[74] A. R. Dennis, B. J. Haley, and R. J. Vanderberg, "A Meta-analysis of effectiveness, efficiency, and participant satisfaction in group support systems research," in Proc. 17th Int. Conf. Inform. Syst., J. I. DeGross, S. Jarvenpaa, and A. Srinivasan, Eds., New York, 1996, pp. 278-289.

[75] R. Johansen, Groupware: Computer Support for Business Teams. New York: The Free Press, 1988.

[76] A. R. Dennis, "Information exchange and use in group decision making: You can lead a group to information, but you can't make it think,” MIS Quart., vol. 20, no. 4, pp. 433-455, 1996.

[77] J. Webster and L. K. Trevino, "Rational and social theories as complementary explanations of communication media choices: Two policy-capturing studies," Acad. Manage. J., vol. 38, no. 6, pp. 1544-1573, 1995.

[78] O. K. Ngwenyama and A. S. Lee, "Communication richness in electronic mail: Critical social theory and the contextuality of meaning," MIS Quart., vol. 21, no. 2, pp. 145-167, 1997.

[79] E. Hutchins, Cognition in the Wild. Cambridge, MA: MIT Press, 1996.

[80] K. Henderson, On Line and On Paper: Visual Representations, Visual Culture, and Computer Graphics in Design Engineering. Cambridge, MA: MIT Press, 1998.

[81] (2000, June) PC Mag.. [Online]. Available: http://www.zdnet.com/pcmag/stories/reviews/0,6755,2586430,00.html

[82] (2000, Sept.) InternetWeek. [Online]. Available: http://www.internetweek.com/indepth/indepth092 500.htm

[83] L. Wasserman, "Live interaction: What's needed on the web," Customer Interaction Solutions, vol. 19, no. 7, pp. 58-61, 2001.

[84] J. Macdonald, "Quality and the financial service sector," Manag. Service Qual., vol. 5, no. 1, pp. 43-46, 1995.

[85] J. Walkins, "Information systems: The UK retail financial services sector," Marketing Intell. Planning, vol. 10, no. 6, pp. 13-18, 1992.

[86] T. Keen, "Email: From simplicity to ubiquity," in Groupware in the 21st Century, P. Lloyd, Ed. Westport, CT: Praeger, 1994, pp. 92-96.

[87] L. Eichler and L. Halperin, "LivePerson: Keeping reference alive and clicking," Econtent, vol. 23, no. 3, pp. 63-66, 2000. 
[88] J. Gilbert, "LivePerson focuses on the human touch," Advertising Age, vol. 70, no. 23, p. 62, 1999.

[89] M. Cracknell, "A cyberstar is born," Marketing Week, vol. 23, no. 45, p. 54, 2000.

[90] A. Orubeondo, "Security and senses enlivened with speech technologies," InfoWorld, vol. 22, no. 42, pp. 86-87, 2000.

Ned Kock is an Associate Professor and the Chair of the Department of MIS and Decision Science in the College of Business Administration, Texas A\&M International University. He holds a Ph.D. in management information systems from the University of Waikato, New Zealand. Kock received the Best Conference Paper Award at the Australasian Conference on Information Systems. He was one of the recipients of the MCB Press Outstanding Paper Award, two MCB Press Highly Commended Paper Awards, and Anbar's Citation of Excellence Award. Kock has authored over 90 conference proceedings papers and articles published in a number of journals including the Communications of the ACM, the IEEE TRANSACTIONS ON EDUCATION, the IEEE TRANSACTIONS ON ENGINEERING Management, the IEEE Transactions on PRofessional Communication, Information \& Management, the Information Systems Journal, Information Technology \& People, the Journal of Organizational Computing and Electronic Commerce, and MIS Quarterly. 


\section{IEEE PROFESSIONAL COMMUNICATION SOCIETY}

\section{Editorial Staff}

\section{Editor-in-Chief}

KIM SYDOW CAMPBELL

Box 870225

Univ. of Alabama

Tuscaloosa, AL 35487-0225 USA

email: k.s.campbell@ieee.org

\section{Book Review Editor}

KATHRYN RILEY

Lewis Dept. Humanities

Siegel Hall

Illinois Inst. Tech.

Chicago, IL 60616 USA

email: kriley@ieee.org

\section{Editorial Assistants}

MARY ALICE ADAMS

NATHAN SHEPLEY

Box 870225

Univ. of Alabama

Tuscaloosa, AL 35487-0225 USA

email: madams@cba.ua.edu

email: nshepley@cba.ua.edu

\section{MICHAEL ALBERS}

Univ. Memphis

CHARlotTe BRAMMER

Samford Univ.

SAUL CARLINER

Concordia Univ.

MARJORIE DAVIS

Mercer Univ.

MARK FREIERMUTH

Univ. Aizu

LAUREL GROVE

Independent

RICHARD HOUSE

Rose-Hulman Inst. Tech.

\section{Editorial Advisory}

ROGER GRICE

52 Doris Lane

Lake Katrine, NY 12449 USA

email: gricer@rpi.edu

Awards

BOB KRULL

LL \& C Dept.

RPI

Troy, NY 12180 USA

email: krullr@rpi.edu

\section{Associate Editors}

NICOLE AMARE, (Industry Practices)

Dept. of English

240 HUMB

Univ. of South Alabama

Mobile, AL 36688 USA

email: namare@usouthal.edu

NeD KocK, (Information Systems)

Dept. of MIS \& Decision Sci.

Texas A\&M Int. Univ.

Laredo, TX 78041 USA

email: nedkock@tamiu.edu

THOMAS ORR, (International, EFL, ESP)

Ctr. for Language Res.,

Univ. of Aizu

Aizuwakamatsu, Fukushima

965-8580 Japan

email: t-orr@u-aizu.ac.jp

\section{Board of Regular Reviewers}

BRUCE HOWARTH

Univ. Tech. Sydney (ret.)

BOB KRULL

RPI

PAUL LOWRY

BYU

JO MACKIEWICZ

Univ. of Minnesota-Duluth

Mary Sue MacNealy

Univ. Memphis

BEGOÑA MONTERO

Univ. Politec. Valencia

PRASHANT NATARAJAN

Auburn Univ.

\section{SOCIETY STANDING COMMITTEES}

Education

JULIA WILLIAMS

Dept. of Humanities \& Social Sciences

Rose-Hulman Inst. Tech.

Terre Haute, IN 47803 USA

email: julia.m.williams@ rose-hulman.edu

Electronic Information

BETH MOELLER

15 1/2 Jumel Place

Saratoga Springs, NY 12866 USA

email: beth@imediaconsult.com
Michael F. STEEHOUder, (Document Design, Applied Linguistics)

Dept. of Comm. Studies

P. O. Box 217

7500 AE Enschede, The Netherlands

email: m.f.steehouder@wmw.utwente.nl

Julia Williams, (Pedagogy)

Dept. of Humanities \& Social Sciences

Rose-Hulman Inst. Tech.

Terre Haute, IN 47803 USA

email: julia.m.williams@ rose-hulman.edu

BOARD OF ADVISORS

ROGER GRICE, RPI

SAUl CARliner, Concordia Univ.

MARK Freiermuth, Univ. Aizu

LAUREL GROVE, Independent

BOB KRULL, RPI

ERIN SCHULZ, Intel

JAN SPYRIDAKIS, Univ. Washington

JOHN T. ORIEL

Independent

JUAN C. PALMER

Univ. Jaume I

ERIN SCHULZ

Intel

KENG SIAU

Univ. Nebraska

TERRY SKELTON

Bentley Coll.

JAN SPYRIDAKIS

Univ. Washington
Membership

SHERRY STEWARD

Dimensions International

12139 Science Dr., Ste. 103

Orlando, FL 32826 USA

email: ssteward@dimen-intl.com

Publicity and Marketing

VACANT 